\title{
Collaboration in Agrotourism Development: The Role of Local Government in Yeongdong County, Chungcheongbuk Province, Korea
}

\author{
Ngo Thi Phuong Lan ${ }^{1 *}$ and Hoang Ngoc Minh Chau ${ }^{2}$ \\ ${ }^{1}$ Associate professor, Faculty of Anthropology, University of Social Sciences and Humanities, Vietnam National University Ho Chi Minh \\ City, Dist 1, Ho Chi Minh, Vietnam \\ ${ }^{2}$ Lecturer, Faculty of Tourism, University of Social Sciences and Humanities, Vietnam National University Ho Chi Minh City, Dist 1, Ho \\ Chi Minh, Vietnam
}

\section{ABSTRACT}

Background and objective: There are many theories related to the development of agrotourism, and each stakeholder has its own role and function. If it is based on organizational functions, stakeholders need to be coordinated, and the state plays a major administrative role. But in the successful case of Yeongdong County, Chungcheongbuk province, the Republic of Korea, the government played an important role in the development of tourism, which grants us another perspective on the role of the government in promotion and development agrotourism activities.

Methods: This article aims to examine the development of agrotourism through a cooperative approach, by clarifying the role of the local authorities in the Yeongdong region in the management and operation of the local agrotourism activities. The qualitative research method is based on a field survey conducted in Yeongdong County in 2019.

Results: The study's findings show that in situations where conflicts of interest among stakeholders are prone to occur, the development of local tourism has a limited impact on the cooperative culture, and local governments play an important role. Accordingly, the local governments must actively formulate strategies to maintain and develop traditional agricultural industries and at the same time develop agrotourism activities. The government's ability to coordinate, cooperate, and participate reasonably is a key factor for the success of the sustainable development of the tourism industry.

Conclusion: Based on coordination between stakeholders and a reasonable strategic direction, Yeongdong's agrotourism is being effectively deployed. The development of Yeongdong's agrotourism industry has achieved impressive results through an effective strategy, highlighting the important role of localgovernment in the consensus of local communities and collaboration with stakeholders. The role of outstanding local governments has been clearly demonstrated, especially in promoting, establishing, and contacting different organizations to effectively deploy agrotourism in the region.

Keywords: agrotourism, collaboration, local government, tourism development

\section{Introduction}

The development of tourism is a means to promote economic development (Lee and Chang, 2008 and Schubert et al., 2011). Therefore, when examining the sustainability of tourism development, research often focuses on cultural and environmental factors (Sharpley, 2009), McCool and Moisey, 2001. But from the perspective of economic development, tourism is a comprehensive sector encompassing many fields and topics, and as such the potential for conflicts of interest exists. Therefore, in ensuring the good operation of the tourism industry, sustainability is also a

This paper is the product of the state-level research project "Developing agrotourism value chains in the Mekong Delta in a new context". Code: KX.01.52 /16-20.

Received: November 5, 2020, Revised: November 16, 2020, Accepted: November 23, 2020

First author: Ngo Thi Phuong Lan, ngophuonglan@hcmussh.edu.vn, (1) https://orcid.org/0000-0002-1061-5418

*Corresponding author: Hoang Ngoc Minh Chau, hoangngocminhchau@hcmussh.edu.vn, (1) https://orcid.org/0000-0002-5765-0149 
factor. To ensure this sustainability, local governments are one of the main stakeholders (Cameron et al., 2001).

Both domestically and around the world, a significant amount of research has been conducted on the role of local authorities as an important public sector entity to promote the sustainable development of tourism. These studies focused on the view that the local government is a functional entity that creates a good environment for the development of tourism. Cameron et al. (2001) asserted that the local government is an important stakeholder in tourism development management. County and city councils have "support" and "tourism management" functions, with the aim of supporting economic development, developing local public utilities and initiatives to attract tourists and promoting promotions through cultural festivals or sports events; and establishing environment, health, safety, and management issues, etc.

In another study, Ruhanen (2013) pointed out that compared with other service industries, economic profit is the driving force for government intervention in tourism. In addition, the author also mentioned that government participation not only could involve economic benefits but also generate income to address the material and social impacts of tourism. As the negative effects of tourism began to cloud the enthusiasm of certain destinations, and with an increase in anti-tourism sentiments, government-led plans were promoted to control the development of tourism and minimize the negative social and economic impacts.

The development of tourism in general, particularly agrotourism, requires connection and collaboration among stakeholders, each of which has its own role and function. This article aims to understand the ways in which stakeholders participate in the development of Yeongdong agrotourism, and specifically discusses the role of local governments in the management, administration, and implementation of local agrotourism collaboration.

\section{The concept of "agrotourism"}

In the past two decades, agrotourism has become a global phenomenon, and many researchers are interested in it. But researchers still do not universally agree on a definition of the concept of "agrotourism." At a generally recognized level, agrotourism is understood as meeting people's needs for entertainment and leisure by using and enjoying material and spiritual values related to agricultural production, animal husbandry, rural areas, and agricultural traditions and customs (Sznajder et al., 2009; Gil Arroyo, 2012). "Agritourism gives people the chance to breathe fresh air, learn about rural environment, ride horses, pick fruits, feed animals, milk cows and participate in actual work of farm and buy produce directly from a farm. Agritourism is a form of niche tourism in which farms are used as tour destinations for educational and/or recreational purposes." Agritourism is, "the practice of attracting travellers or visitors to rural areas which are used primarily for agricultural purposes" (Surabhi, 2016).

"Agrotourism" refers to all tourism and leisure activities related to agriculture, plantation, fishery, or agribusiness organizations, and is considered synonymous with farm-based tourism (Przezborska, 2005), and is an inherent part of the concept of rural tourism. As Benard (2012) said, the concept of "rural tourism" includes "agrotourism," and agrotourism is the origin of rural tourism (Benard, 2012). Rural tourism has the nature of variety and diversity (Lane, 1994; Roberts and Hall, 2001) while agrotourism can be seen as a segment of rural tourism (Wilson et al., 2001) because it is "located in rural areas; functionally rural; rural in scale, traditional in character; growing slowly and organically; and connected with local families; and representing the complex pattern of rural environment, economy, history and location" (Lane, 1994).

In Italy, the development of agrotourism took place relatively early; the Italian government introduced the definition of agrotourism in the 1985 National Law. As such, agrotourism is understood as a tourist activity that welcomes agribusinesses and their families, and must be closely related to agricultural activities (Pauline, 2009). Understandably, this definition shows that the connotation of the concept of "agrotourism" includes three basic elements: (1) its activities take place on a farm serving tourists, (2) activities are related to agriculture, and (3) agrotourism business activities are organized, operated and managed by farmers and their families.

In summary, the main content related to agrotourism should be understood as (1) Combining tourism and agri- 
culture to attract tourists to visit agriculture-related activities; (2) Its main purpose is to increase incomes for farmers; (3) Its activities are designed to provide tourists with entertainment and physical and mental exercise, get close to nature, and experience farmers' lives; and (4) It is characterized by combining rural natural value and traditional cultural value. The development of agrotourism helps protect tangible and intangible cultural heritages and traditional occupations. Therefore, this study mainly uses the above-mentioned connotation of the concept of "agrotourism."

\section{Collaboration in the development of tourism and the role of local governments}

\section{Collaboration in the development of tourism}

The concept of "collaboration" was defined by Gray (1989) as "a process through which parties who see different aspects of a problem can constructively explore their differences and search for solutions that go beyond their own limited vision of what is possible." Therefore, a collaborative alliance is the result of an effort by many related organizations to solve overly complex problems through independent actions (Gray and Wood, 1991). Accordingly, "collaboration occurs when a group of autonomous stakeholders of a problem domain engage in an interactive process, using shared rules, norms and structures, to act or decide on issues related to that domain" (Gray and Wood 1991).

Collaboration involves the relationship between stakeholders when these stakeholders interact with each other on a common issue or "problem domain." Each stakeholder controls resources, such as knowledge, expertise, constituencies, and capital, but may have their own future with regard to major tourism development issues (Bramwell and Lane, 2000).

Collaboration is considered essential to the sustainable development of tourism. Studies by Selin (1999), Bramwell and Alletorp (2001) and Bramwell and Lane (2005) all agree that interdisciplinary collaboration will help achieve sustainable development. The core role of sustainable destination management involves setting common goals to establish a framework for common action (Berresford, 2004). Some potential benefits of collaboration in tourism planning are summarized by Gray (1996), Huxham (1996),
Bramwell and Lane (2000), and include involvement by a range of stakeholders; the diffusion of decision-making power and control to multiple stakeholders; an increase in the social acceptance of policies; more constructive and less adversarial attitudes; the knowledge, regime and capacity difference stakeholders bring to the policy-making process; the potential for greater innovation and effectiveness; the promotion of group interaction and negotiation skills; greater commitments; improved coordination; greater consideration of the diverse economic, environmental, and social issues; and greater recognition of the importance of non-economic issues and interests, among others.

A collaboration framework developed by Bramwel and Sharmen (1999) identifies three types of issues, which should be considered when examining partnerships related to local tourism policy-making prior to policy implementation. The first of these concerns the scope of each partnership. Here, we identify a key question, which is whether the scope of participating stakeholders represents all stakeholders affected by one or more issues. The second set of issues highlighted by Bramwell and Sharman concerns the strength of collaborative relations between relevant stakeholders. The third group focuses on the degree of consensus between stakeholders in the partnership (if this happens).

Gray (1996) specifies the collaboration model and outlines the three-phase framework of the collaboration process. In the first phase, in order to solve the problem, multiple stakeholders are required to agree on the problem, and to agree that the problem is important enough to find a solution with others. In addition, this phase must ensure that all stakeholders are included to fully understand the process. If the key stakeholders are excluded from this phase, Gray believes this may cause technical or political issues during the implementation phase of the collaboration (Gray 1989; see further De Araujo and Bramwell 2002; Jamal and Stronza 2009). The direction setting of the second phase focuses on establishing rules, groups, and agreements between stakeholders. In addition, the second phase requires the exploration of various options by discussing the interests and values of each group, and then finally reaching an agreement to continue to take specific actions (De Araujo and Bramwell 2002; Jamal and Stronza 2009). In the final phase of the collaboration, one will see the 


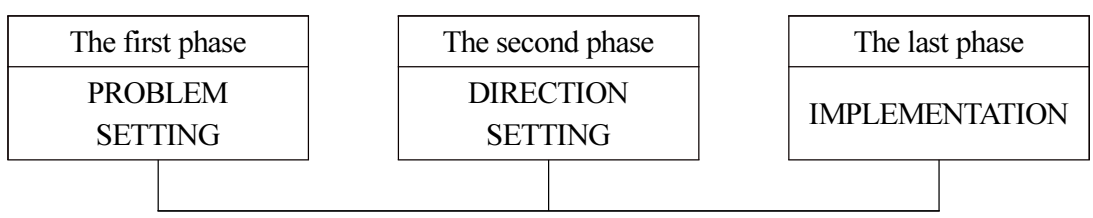

Fig. 1. Stakeholders' collaboration model. Reprinted from Cross-sectoral partners: Collaborative alliances among business, government and communitie, by Gray, B., 1996, Copyright 1996 by Sage Publications.

implementation of the selected action plan, which requires support and structure, including monitoring of compliance (De Araujo and Bramwell 2002; Jamal and Stronza 2009).

In the past decade, the application of collaborative theory in tourism planning, management and development has become very common to help manage emerging environmental issues such as climate change, loss of biodiversity, resource depletion and the impact of globalization (Selin 1999; Plummer et al., 2006; Jamal and Stronza 2009). As tourism is a complex industry that affects multiple groups (Hardy and Beeton 2001; De Araujo and Bramwell 2002; Jamal and Stronza 2009), there are challenges in implementing collaboration (De Araujo and Bramwell 2002). Specifically, in the tourism industry, each group's interests and influence on decision-making will be different at local, regional, or national levels (Jamal and Stronza 2009).

Based on theories and works close that approach this point of view, this article uses Gray (1996)'s model to clarify the role of local authorities in collaboration with other participants in the construction and regulation of agrotourism activities in Yeongdong County, South Korea (Fig. 1).

\section{Research Methods}

\section{Methodology}

The paper uses qualitative research methods, and its main data is collected from reports, academic papers, books, etc. on the Internet. Furthermore, the team conducted an 11-day field survey in Yeongdong from November 9 - 19, 2019. During the investigation, the research team gave a seminar and held 10 in-depth interviews with the members of local government agencies on agriculture and tourism and families carrying out agrotourism activities, including the Mayor of Yeongdong District People's Committee, the
Deputy mayor of Yeongdong District People's Committee, the Director of the Korea Wine agrotourism experience area, the owner of Country Wine local makers, the owner of Miso local wine makers, the owner of Yeongdong Dried Persimmon factory, the managing board of Yeongdong Wine Tunnel tourism area, the Managing board of an agricultural cooperative, a representative of U1 University, the managing board of Yeongdong Traditional Music Culture Experience Village, the managing board of Agrotourism Experience Village; etc. Dialogues and in-depth interviews were conducted in Korean, through an interpreter who translated into Vietnamese.

In particular, at the request of Yeongdong county, a seminar was organized for the purpose of understanding the development and implementation of agrotourism activities in Yeongdong County. The chairman of the People's Committee of Yeongdong County appointed relevant departments and specialized officials to participate in the seminar, including a representative of Yeongdong County; officers of the agricultural technical center; an officer in charge of rural areas; an officer in charge of forests and forest products; officials responsible for the environment and supporting the environment; an officer responsible for human resource development; an officer in charge of rural resources; an officer in charge of alcohol-related affairs; an officer in charge of research and development; an officer in charge of agricultural machinery and technology; and an officer in charge of immigration in Yeongdong County.

The families selected for in-depth interviews are local families of long standing in the region, families with vineyards and winemakers, who organize activities and experience services, such as serving customers to appreciate products, visiting production processes, discussing products with landlords, and selling products.

These families understand the history and development process of the area, and have won reputation and awards 
during the development process. In-depth interviews with these families will help the research team fully understand agrotourism activities in the Yeongdong region. In addition, the county also introduced our research team to investigate functional areas related to agrotourism experience activities such as the Wine Tunnel Tourism Area, agricultural experience villages, local cultural experience villages, etc.

\section{Study area}

Yeongdong is a county (district) of Chungcheongbuk-do (province) in the heart of South Korea. The latitude and longitude of Yeongdong County are $36^{\circ} 01^{\prime} \sim 36^{\circ} 19^{\prime} \mathrm{N}$ and $127^{\circ} 04^{\prime} \mathrm{E}$, respectively (Fig. 2). It is located at the northernmost point of Chungcheongbuk province, with Jincheon and Sangju of Gyeongsangbuk province to the east, Geumsan-gun of Chungcheongnam province to the west, Muju-gun of Jeollabuk province to the south, and Okcheon-shot to the north. In terms of Yeongdong's distance from major cities in South Korea, it is 193.8 kilometers from Seoul, 74.2 kilometers from Cheongju, 41.5 kilometers from Daejeon, 95.9 kilometers from Daegu, 234.2 kilometers from Busan, 212.2 kilometers from Gwangju, and 284.1 kilometers from Wonju. The county has an area of 845.4 square kilometers, accounting for $0.85 \%$ of the national territory and $11.4 \%$ of the provincial territory. $77.8 \%\left(658.29 \mathrm{~km}^{2}\right)$ consist of forests and fields, while $14.1 \%\left(119.2 \mathrm{~km}^{2}\right)$ is farmland and $8.1 \%\left(68.70 \mathrm{~km}^{2}\right)$ is land of other types. The population of Yeongdong County was 57,424 in 2001 , but had decreased to around
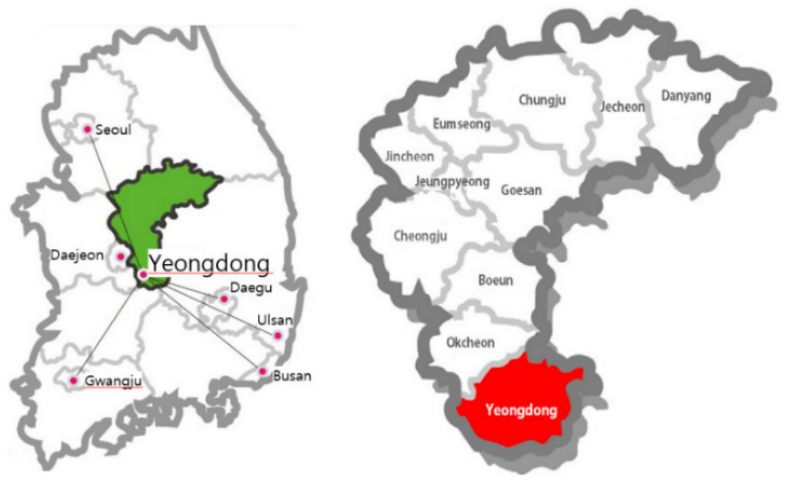

Fig. 2. Location of Yeongdong County, Chungcheongbuk Province, South Korea
50,000 by 2019 (Yeongdong County People's Committee 2019).

Yeongdong is Korea's largest grape-growing county, accounting for $15 \%$ of Korea's total grape production. In Yeongdong, there are 4,100 agricultural families planting grapes on 2,200 hectares of land, with an annual output of more than 45,000 tons. The total income of related industries is approximately 100 billion Korean Won (KRW). The Yeongdong grape industry cluster started in 2005, and its economic impact increased farmers' incomes by $40 \%$ by 20081).

The agricultural experience activities available to Yeongdong tourists include experiencing the wine production process, visiting the orchard, talking with winemakers and garden owners, tasting wine, picking grapes, pickling grapes, mashing grapes, immersing one's feet in wine, enjoying live music performances, learning musical instruments, learning to make traditional Korean food and tok cakes, planting and harvesting seasonal fruits, and more.

\section{Results and Discussion}

\section{History of agrotourism development in Yeongdong County}

Agrotourism in Yeongdong County started in the 1990s. At this time, households with orchards (grapes, persimmons, etc.) were open to visitors. But this kind of agrotourism failed both from an agriculture and a tourism perspective. In terms of agriculture, when gardeners were open to visitors, it affected the ecology, soil, and root system of the garden, leading to the destruction of the garden and its ecology. At the same time, tourists who came to take pictures were bored, so from an experience point of view, the organization of this service could not meet the needs of tourists. Therefore, the first stage of Yeongdong's agrotourism activities was not well developed. Until 2008, the grape-wine agrotourism model was developed and implemented locally (Source: information gathered through

1) Yeongdong County. 2011. "A Case of Vitalizing Regional Economy through the Convergence of High Added Value Grapes Industry." 2011 Vision Leadership Forum. 


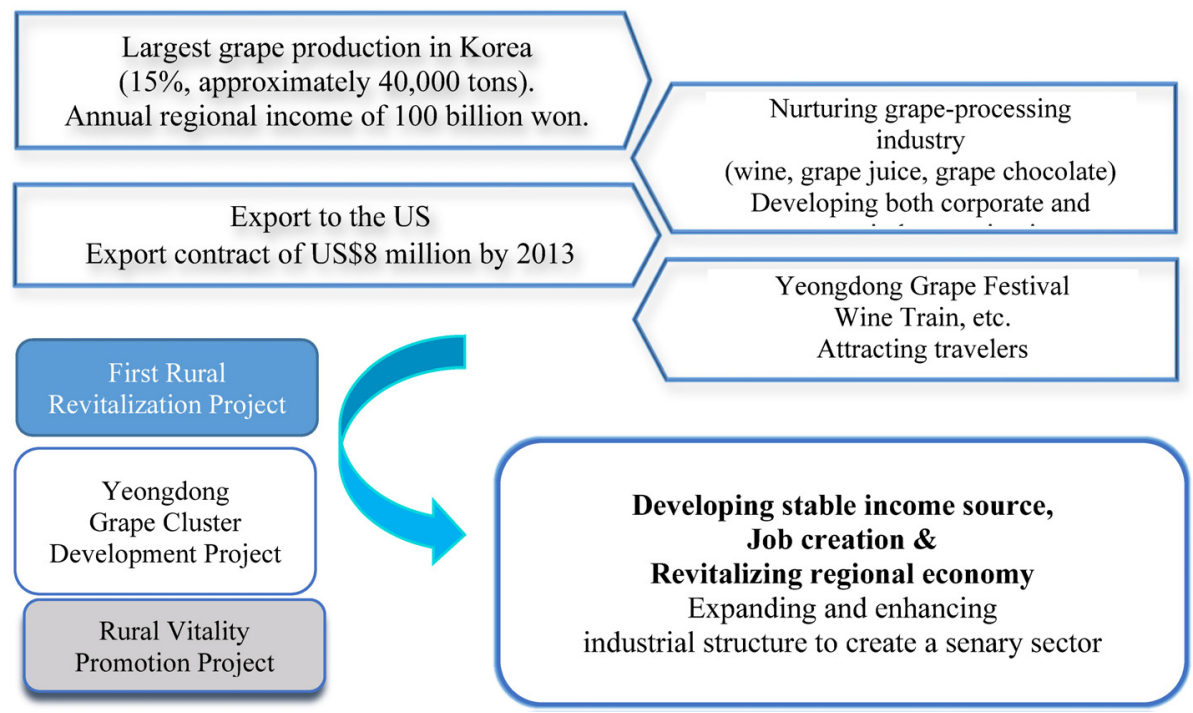

Fig. 3. Strategies for the development of agrotourism related to grape growing and grape processing industry in Yeongdong County. Adapted from KIET (2004), and Yeongdong County (2019).

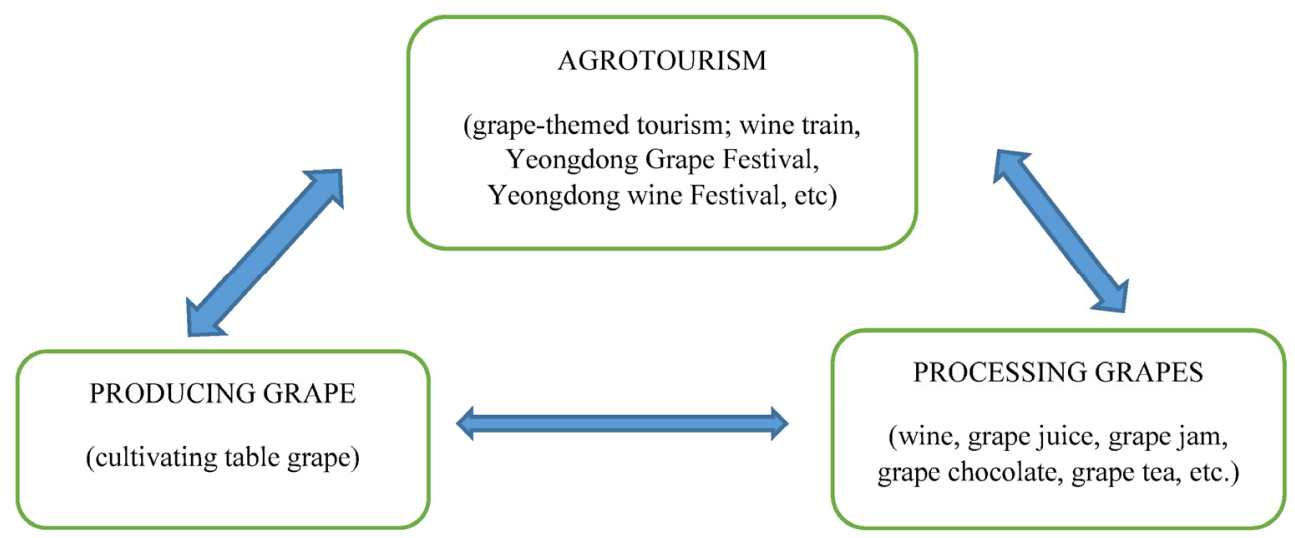

Fig. 4. Agrotourism related to grape growing and grape processing industry in Yeongdong County. Adapted from KIET (2004), and Yeongdong County (2019).

the seminars and in-depth interviews, 2019).

In 2005 the Yeongdong Grape Industry Cluster was designated by the central government as a "special zone for grape and wine industry" (Figs. 3, 4). The Yeongdong Grapes Cluster was a successful example of creating synergy through the combination of industries; in this case, grape production, processing, and agrotourism (KIET, 2004; in-depth interview information). As the nation's biggest grape grower, Yeongdong county is expanding from table grapes into producing wine, jam and grape juice, and developing tour packages including wine festivals, a wine train, and experiences at local wine makers (Fig. 4).

Through the investigation, the team studied the agro- tourism operation system in Yeongdong County as shown in Fig. 5 below. Fig. 5 describes how to implement and operate agrotourism activities in Yeongdong by connecting with participants in the value chain that provide tourist services to tourists.

Tourists (groups) book trips from Seoul through local travel agencies. One of these local agencies will connect to the Seoul-based travel company which is designated by the Yeongdong County. This designated Seoul-based travel company is also connected to the KoRail train to bring tourists to the area every Tuesday and Saturday. When the train arrives at the local Yeongdong station, there will be local buses to take tourists to sightseeing spots. This bus 


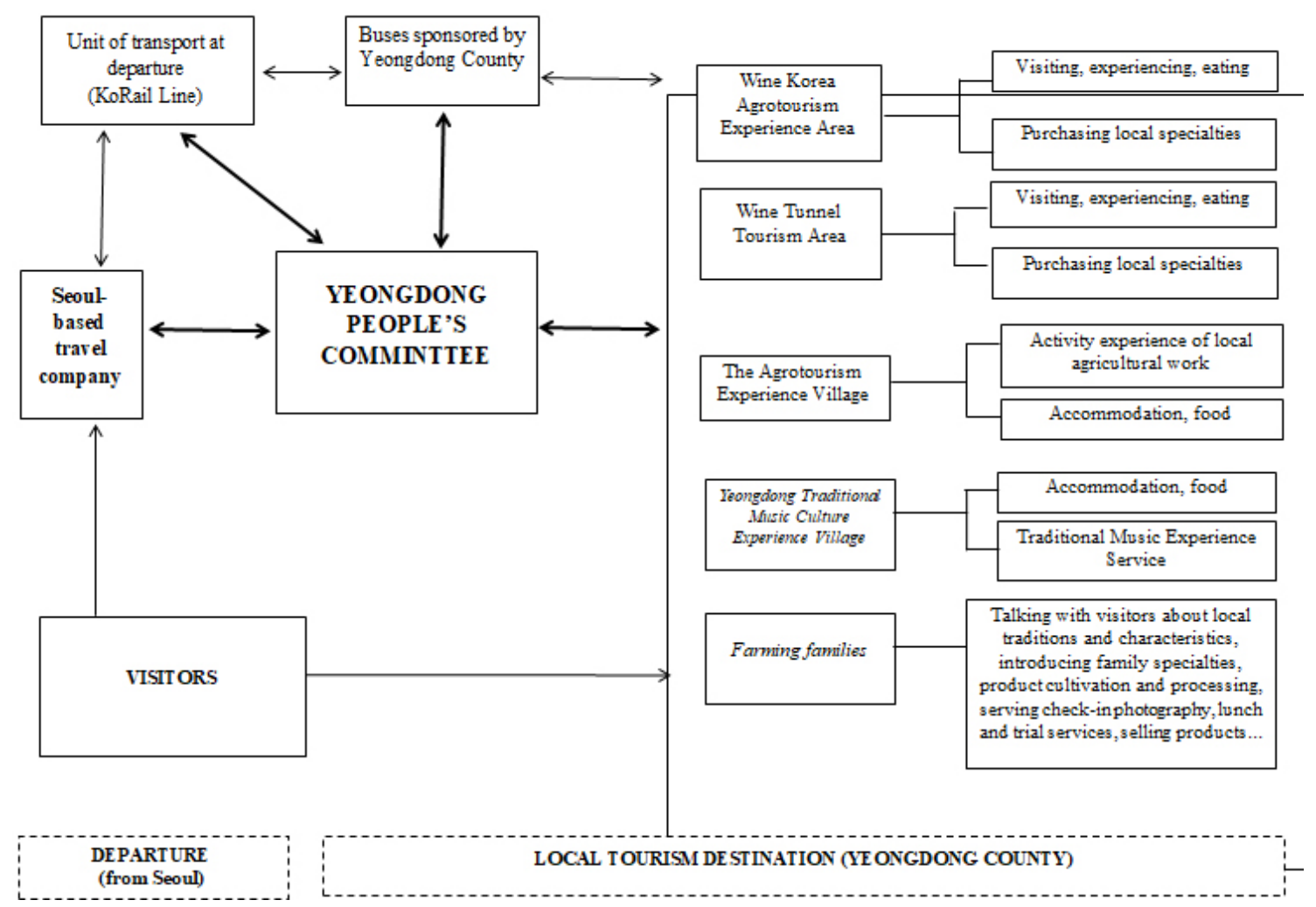

Fig. 5. Agrotourism activities in Yeongdong County, South Korea. Adapted from KIET (2004) and synthesized from in-depth interviews (2019).

system is sponsored by Yeongdong County, and is free for tourists (Source: Yeongdong County).

In the local area, there are many places to visit and experience local specialties. These places are operated by farmers themselves, and some are developed and operated with tourism as part of their business model, specializing in tourism services provided to tourists. Grape wine tasting areas and vineyards (such as Korea Wine, Country Wine), and local farming families are open to tourists. In addition, there are many other tourist experience points, such as the Wine Tunnel Tourist Area, agrotourism experience villages, local cultural protection experience villages, etc., to diversify tourism services. Other popular tourist attractions in the area, such as Peace Village, local markets, local restaurants, specialty restaurants, etc., really attract tourists. Most of these experience points provide lunch for travelers or allow guests to order meals. Some offer restaurant services (in the resorts) where guests will dine on-site during the trip.

According to Fig. 5, the objects of agrotourism activities in Yeongdong Country include local authorities, tourism companies, families who welcome tourists to experience the family's agricultural activities, the Agrotourism Experience Villages, the Wine Tunnel Tourist Area, the Korean Traditional Music Culture Experience Village, etc. Each object has its own function, and all are coordinated smoothly.

- Local authority, i.e., the Yangdong County Government in this study, mainly issues the policy, urges stakeholders to take action, and sets appropriate policies and mechanisms to coordinate lower-level departments and stakeholders.

- Tourism companies are in charge of organizing contact with the market, bringing guests from outside to Yeongdong to experience the region, developing tourist routes, connecting different destinations and operators to serve tourists.

- Farming families provide their own garden-style travel experience (grapes, apples, etc.) and allow visitors to observe their own winemaking process at home. They talk to visitors to help them feel satisfied with 
questions related to grapes and wine.

- The Agrotourism Experience Village is built by the county government, and often organizes interesting activities such as cooking and playing games. The village mobilizes families to guide tourists. In terms of gardening activities, visitors are able to visit gardens directly at people's homes. Then, according to the season and the condition of the home gardens, the management committee will select the appropriate garden for visitors. The Agrotourism Experience Village has a large area, and is specially designed for joint agricultural production. Families with available garden land in the area are encouraged to join the Village and share common activities. Currently, the members of the village management committee are elderly men elected by the families. People with skills and enthusiasm can communicate and tell interesting stories to attract tourists. The Village also has a lodging area for tourists. Promotional activities are carried out through the village homepage, provincial and county people's committee websites, county education bureau websites, etc. (Source: in-depth interview information, 2019)

- The Yeongdong Wine Tunnel Tourist Area is planned to cover an area of 77,950 square meters and is expected to be completed in 2021. The total investment in its development is 267 billion Korean Won (KRW). Of this, 140 billion KRW will be provided by Yeongdong County, and 127 billion KRW will be mobilized from shareholders (local residents). The tourist area is used as a wine museum to display and introduce the wine production history, the production process, and local wine products of Yeongdong County as well as the history of world-famous wines. In addition, there are other activities in the area, such as wine tasting, entertainment, photography, introducing local culture and history, restaurants, local specialties, souvenir service, and more (Source: Yeongdong County People's Committee \& fieldwork results).

- The Korean Traditional Music Culture Experience Village was established in 2015 to provide tourists with services to experience and practice traditional local musical instruments. The Village offers 43 rooms that can accommodate up to 200 guests. The promo- tion activities are introduced through the website of Yeongdong County, Facebook, and information corners on the wine train. Artists participating in village performances are paid by Yeongdong County (Source: in-depth interview, 2019).

Through the above operating model, local participants can benefit from participating in agrotourism. That is the share of profit shared through links with travel agencies. In addition, through the experience at the destination, visitors will purchase local specialties. For local farmers, the main basis of their income is agricultural activities, and they have greatly increased their incomes through the integration of agriculture and tourism, and also have promoted the growth of agricultural product sales. When tourists visit, these families will also find more vitality and happiness, which can help agricultural activities flourish in a very positive way.

According to Fig. 5, the results show that all stakeholders play an important role in the development of agrotourism activities in the Yeongdong region. Among them, the local authority in the region is the center, which plays an important role as an intermediary between the external and local tourist markets, establishing and deploying agrotourism mechanisms, and connecting all relevant entities.

\section{Collaboration in the development of tourism agricultural activities - the local government activities}

Based on the analytical framework proposed by Gray (1996), this paper analyzes the collaborative relationship to clarify the role of local authorities in the management and implementation of agrotourism activities in the Yeongdong region of South Korea.

\section{The first phase - Problem Setting}

In this phase, stakeholders identify and determine the problem(s) to be solved. Through our in-depth interviews, we found that in the 1980s, South Korea's economy was in decline, and the Yangdong area was also severely affected. As a result, household incomes were reduced, affecting families' budgets for food expenditures and lowering the consumption of fresh fruit after meals as a result. 
This is why the consumption of fresh grapes nationwide was greatly reduced. Yeongdong County has historically been an area that specializes in grape cultivation, and provided a large number of grapes for the market. With a poor economy, the local grape growing industry was facing difficulties, the yield of grapes was not being sold as expected, and the lives of the people were severely affected. This situation served as a wake-up call that could help stakeholders identify problems, determine the appropriate direction, and recover for themselves and the local economy (Source: in-depth interview information, 2019).

According to our in-depth interviews with the chairman of Yeongdong County and local families, the chairman of Yeongdong County met with a grape grower (later the owner of Korea Wine Company) and some friends, and brainstormed to find solutions that would revitalize agricultural activities and the local economy. It is important to note that these people were classmates and local friends of the same age who had previously established mutual understanding and trust between each other, and they all had a good vision for life, good social status, and good experience in political and economic achievements. In this context, the stakeholders had a good environment for dialogue that could promote mutual exchanges and collaboration. They were determined to sit together and find a way forward, for themselves and the local area (Source: in-depth interview information, 2019).

From this starting point, the idea was to shift from pure grape cultivation to wine production and its related services (agrotourism based on grape cultivation and wine production).

\section{The second phase - direction setting}

In the problem determination phase, it is necessary to communicate with stakeholders and reach a consensus. The key participants must be strong and able to create a policy and implementation environment. The themes are interrelated and have an interdependent relationship to correctly identify the problem and call for collective action to solve the problem(s) consistently. Stakeholders must acknowledge each other's problems. The goal of this phase is that stakeholders will unanimously exchange views and commit to the process of collaboration and operation.

It is worth mentioning that the central government's support in the strategic direction of Yeongdong's development is carried out on the basis of the consensus of all stakeholders.

Specifically, in 2005, according to the policy of the central government, the Yeongdong vineyard area was designated as a "special area for the grape and wine industry" with a budget of approximately 9.3 billion KRW ( $40 \%$ by funded the central government, $40 \%$ by local governments, and $20 \%$ by businesses). This budget was invested in a number of projects to create infrastructure for the grape industry between 2005 and 20092). The main projects include operating cluster organizations, establishing a ubiquitous network, providing technical support at business sites, formulating and operating educational programs for major innovation agents, promoting the grape processing industry, and establishing and operating a grape processing technology center, establishing grape processing plants, organizing professional companies for distribution and marketing, building high-quality co-brands, and running hands-on experience programs for tourists (Lee, 2008).

In addition, the Project to Revitalize Farming Villages (2008 2010) effectively supported the "Fruits and Traditional Music: Global Yeongdong Marketing" program (Song, 2013). Then, through the first phase of the revitalization plan (2005 to 2007), 2.5 billion KRW was invested annually for three years, and 12 projects were implemented in three areas, including enhancing innovation capabilities, promoting traditional Korean music, and positioning Yeongdong as a national traditional music center.

According to KIET (2004), both private and public stakeholders in the area need to share ideas and collaborate voluntarily through similar visions. All relevant actors and organizations in Yeongdong are working hard to achieve common goals. The Grape Specialization Project Team,

2) The Regional Agricultural Clusters Project is a new model for agricultural development in the region that was started in 2005. It aims to bring innovation in agriculture and to increase income for farming villages. The goal is to link related industries such as production, processing, and distribution/marketing with farming village tours, industries, universities, research labs, and government organizations in the region that worked together on establishing networks, improving production infrastructure, accelerating industrialization process and helping marketing activities. 
Yeongdong County Office, Agricultural Technology Center, Rural Development Administration, Grape Research Institute (Chungcheongbuk Agricultural Research Institute), Yeongdong University, Wine Korea Company, etc., and other grape growers work closely together through active communication to jointly support the goal of regional development (see KIET, 2004; in-depth interview information, 2019).

\section{The last phase -implementation}

At this phase, a collaborative relationship is formed with stakeholders, and roles and tasks are established for all parties so that they can collaborate effectively in the strategic direction. With regard to agrotourism activities centered on Yeongdong County, many administrative departments are responsible for coordination and implementation.

Support plans from the central government are needed to increase value-added resources for rural areas. The South Korean government supports plans to cultivate vineyards in the area, establish processing centers in specialized farming areas, and provide technical training, start-up support, and R\&D projects. Through these government plans, Yeongdong is able to develop processing centers to directly create high added value for pure fruit planting companies and families (KIET, 2004).

In addition, different stakeholders play different roles in cooperation in the development of agrotourism activities in the Yeongdong region. Specifically, as far as the role of the Yeongdong County Civil Affairs Department is concerned, it is a supporter of policies, motivating stakeholders to take action, and formulating appropriate policies and mechanisms for other departments and stakeholders to work together smoothly.

According to the in-depth interviews, in the first phase, Yeongdong County invested 100 million KRW to purchase 7 wine trains and provided experience tour services for tourists in Seoul (in-depth interview information, 2019). In addition, Yeongdong County also supported leading group training, tourism training courses on tourism service skills. They organized about 100 hours of training, 6 times a year. Yeongdong County provided start-up funds. During the operation period, Yeongdong County provided assistance for agricultural materials and technologies (buckets, pots, etc.); supported professional training courses, and provided funds and tools for farmers' production (in-depth interview information, 2019).

Local authorities pay special attention to promoting the local image to the outside world. Specifically, on the KoRail trains (Wine Trains), images of Yeongdong wine bottles are advertised. On local buses in the county, there are also pictures of Yeongdong grapes, grape products, and local logos (Field survey results, 2019). The local government has also invested in the promotion and sale of agricultural products by placing TV commercials on home shopping channels. Yeongdong County holds 4 local fruit/agroproducts festivals and wine festivals every year based on the characteristics and main fruit(s)/product(s) of the season (persimmons, grapes, wine, etc.). According to Kim (2017), Yeongdong Grape Festival focuses on the production company with its own "Wine Korea" brand in Yeongdong County. The event was supported by the local government. This Festival is considered to remain in a marketing strategy level focused on the primary value of grapes as an agricultural product (Kim, 2017).

In addition, the role of tourism, communities, and educational institutions is very important for keeping in line with policies and participating in the local agrotourism development process. Each unit and stakeholder is responsible for a specific stage or function. For example, a travel company based in Seoul establishes and operates a travel plan from Seoul to Yeongdong; the transportation companies cooperate with the local authorities to build and operate the railway line from Seoul to Yeongdong; local tourist buses are in charge of picking up tourists and transporting them to tourist destinations; local families are in charge of providing tourist services, etc.

Local families play an important role in the cultivation of grapes, persimmons, apples, etc. and wine production. At the same time, they actively decorate the homes as beautiful spaces and welcome guests to experience the agricultural products produced by their family. The owner of the family will self-cultivate to receive, serve, and capture the needs of tourists, so as to provide tourists with products and services that suit their needs.

Regarding educational organization activities, local governments coordinate with local universities (Ul university) 
to develop training plans and organize courses according to local needs. Regular courses are organized to provide wine training and winemaking techniques. Foreign experts are invited to evaluate wine quality and guide farmers to produce wines that meet international standards. In addition, there are training courses in tourism and customer service for local families.

The community's confidence in the management mechanism of local government has increased. Local governments have very consistent management mechanisms and support farmers. All the families interviewed said that the local government has been accompanying them, listening to their opinions in a timely manner, and solving the difficulties of farmers. The leaders of the Yeongdong County People's Committee have taken "dare to think and dare to do" as their working motto to help farmers feel safe and consistent with local policies and guidelines. They are determined to implement and operate the guidelines and plans issued and directed locally.

\section{Comprehensive Discussion}

The relationship and collaboration between stakeholders, as well as the agrotourism activities in Yeongdong County, has resulted in many great achievements and contributed to local development. Since 2008, the county has switched from traditional crops to growing grapes for wine production, successfully revitalizing the local economy. This transformation requires consistent policies and the determination of the government and local communities. The data shows that after ten years, South Korea has obtained about 90 alcohol production licenses; of these licenses, Yeongdong County has obtained nearly $50 \%$ and is considered to be the largest wine production center in South Korea. Yeongdong wine brands are favored by both domestic and foreign markets (Source: Yeongdong County People's Committee, 2019). Therefore, in this Yeongdong region, agrotourism activities are also developing towards the development of the wine industry and other types.

Local agrotourism activities have brought many benefits to participating stakeholders. First, the local entity obtains profits from the travel business linked to the Seoul travel agency. Secondly, through the visitors' experience activities on-site, visitors will buy local specialties. In addition, the main basis of local farmers is agricultural activities; through the links with tourism, families have greatly increased their incomes and promoted the growth of agricultural sales. As well, when visitors come to visit the families, the families will find more vitality and feel happier. This helps agricultural activities to flourish in a very positive direction. The local agricultural sector has obtained a new energy source and has generally sustained agricultural activities, particularly agrotourism (in-depth interview information, 2019).

The results of our analysis show that based on coordination between stakeholders and a reasonable strategic direction, Yeongdong's agrotourism is being effectively deployed. This finding is similar to the findings of previous studies on agrotourism in other places, including those by Timothy (1998), Augustyn (1998); Jewell et al. (2004); Topçu (2007), Bilgen et al. (2014) and Cameron et al. (2001). Augustyn (1998), Jewell et al. (2004), and Topçu (2007) also pointed out in their research that the factors that have a positive impact on the success of agrotourism are the participation and collaboration of stakeholders and local communities. The success of agrotourism is not accidental, nor is it the result of the efforts of any individual or group, but the effective use of many stakeholders to shape and develop the value of agrotourism in rural areas and farmers.

Regarding the role of local government, Cameron et al. (2001) also believed that local governments play an important role in the development of sustainable tourism through two main tasks. The first is to create an environment conducive to the development of tourism, and the second is to establish an effective tourism management mechanism. Another case study in Yeodong County, Chungcheongbuk province, South Korea showed that collaboration of stakeholders and consistency of county policies are two key factors for the development of agrotourism activities. Among these, the role of the local government is, with Yeodong County as the center, an important intermediary between the external market and the local market. They are the units that establish and implement mechanisms and communicate with stakeholders involved in the local agrotourism industry.

In addition, Yeongdong County has successfully selected suitable local agricultural products to develop agrotourism. The development of specific tourism products based on lo- 
cal advantages and agricultural products is considered to be one of the decisive factors in the successful development of agrotourism. In addition, our findings related to the development of agrotourism in the Yeodong region have also reinforced the findings of Topçu et al. (2007). His research shows that agrotourism can be used as a tool for rural development in areas with the potential for the agricultural economy and tourism development.

Back in Yeongdong County, the local agrotourism development has a clearer understanding of how to develop agrotourism in the local area and how stakeholders can work together to achieve their goals. The role of outstanding local governments has been clearly demonstrated, especially in promoting, establishing, and contacting different organizations to effectively deploy foreign tourism in the region.

\section{Conclusion}

The development of tourism is a way to promote economic development. For this reason, research on the sustainability of tourism development usually focuses on cultural and environmental factors. But from an economic development perspective, since tourism is a comprehensive industry that includes many different fields and participants, there are many potential conflicts of interest. Therefore, ensuring the good operation of the local tourism industry is one of the factors of sustainability, and in ensuring this sustainability, local governments are one of the important stakeholders.

In many theories about tourism development, each stakeholder has its own role and function. If it is in accordance with organizational functions, they need the collaboration of stakeholders mainly managed by the government. But in the success of Yeongdong County, in Chungcheongbuk Province of South Korea, the government played an important role in the development of tourism, and the details of the development of the tourism industry here provide another perspective on the government's role in the construction and development of agrotourism activities in the region.

The findings of our research in Yeongdong County, in Chungcheongbuk Province of South Korea, show that in the development of local agrotourism, local governments play an important role in active construction and collaboration to ensure sustainability, especially when there may be conflicts of interest between the main stakeholders and the collaborative culture is restricted. The ability of the government to coordinate the appropriate cooperation and participation of government departments and the consensus of the community and stakeholders are key factors for the successful realization of sustainable tourism development through the construction and development of local agrotourism.

\section{References}

Augustyn, M. 1998. National strategies for rural tourism development and sustainability: the Polish experience. J. Sustain. Tour. 6(3):191-209. https://doi.org/10.1080/0 9669589808667311

Berresford, J. 2004. Tourism in the Region. Reg. Rev. Hear. $1-11$.

Bramwell, B. and A. Sharman. 1999. Collaboration in local tourism policymaking. Ann. Tour. Res. 26(2):392-415. https://doi.org/10.1016/S0160-7383(98)00105-4

Bramwell, B. and B. Lane. 2000. Collaboration and partnerships in tourism planning. In: B. Bramwell \& B. Lane (Eds.), Tourism collaboration and partnerships: Politics, practice and sustainability (pp.1-19). Clevedon, UK: Channel View Publications.

Bramwell, B. and B. Lane. 2005. Sustainable tourism research and the importance of societal and social science trends. J. Sustain. Tour. 13(1):1-3. https://doi.org/10.108 0/17501220508668469

Bramwell, B. and L. Alletorp. 2001. Attitudes in the Danish tourism industry to the roles of business and government in sustainable tourism. Int. J. Tour. Res. 3(2):91-103. https://doi.org/10.1002/jtr.242

Cameron, A.M., A. Memon, D.G. Simmons, and J.R. Fairweather. 2001. Evolving role of local government in promoting sustainable tourism development on the West Coast. (Report No. 28). Retrieved from https:/hdl. handle.net/10182/166

De Araujo, L. M., and B. Bramwell. 2002. Partnership and regional tourism in Brazil. Ann. Tour. Res. 29(4): 
1138-1164. https://doi.org/10.1016/S0160-7383(02)00033-6

Gray, B. and D.J. Wood. 1991. Collaborative alliances: Moving from practice to theory. J. Appl. Behav. Sci. 27(1):3-22. https://doi.org/10.1177/0021886391271001

Gray, B. 1989. Collaborating: Finding common ground for multiparty problems. San Francisco, USA: Jossey-Bass Publishers.

Gray, B. 1996. Cross-sectoral partners: Collaborative alliances among business, government and communities. In: C. Huxham (Ed.), Creating collaborative advantage (pp. 57-79). London, UK: Sage Publications.

Gil Arroyo, C. 2012. What is agritourism?: reconciling farmers, residents and extension faculty perspectives. Master's thesis, University of Missouri, Columbia, USA.

Hardy, A. and R. Beeton. 2001. Sustainable tourism or maintainable tourism: Managing resources for more than average outcomes. J. Sustain. Tour. 9(3):168-192. https://doi.org/10.1080/09669580108667397

Huxham, C. (Ed.). 1996. Creating collaborative advantage. London, UK: Sage Publications.

Jamal, T. and A. Stronza. 2009. Collaboration theory and tourism practice in protected areas: Stakeholders, structuring and sustainability. J. Sustain. Tour. 17(2):169-189. https://doi.org/10.1080/09669580802495741

Jewell, B., A. Blackman, A. Kuilboer, T. Hyvonen, G. Moscardo, and F. Foster. 2004. Factors contributing to successful tourism development in peripheral regions. J. Tour. Stud. 15(1):59-70. Retrieved from https://searc h.informit.com.au/documentSummary; $\mathrm{dn}=200501369 ;$ re $s=$ IELAPA

Korea Institute for Industrial Economics and Trade [KIET]. 2004. Planning urban and rural zones for industrialization. 2013 Knowledge Sharing Program with Ecuador: Policy consultation designed to help Ecuador bolster its economic capability. Sejong, Korea: Ministry of Strategy and Finance.

Kim, K.S. 2017. Local Festival and Culture Contents. J. Korea Converg. Soc. 8(7): 183-189. https://doi.org/10.1 5207/JKCS.2017.8.7.183

Lane, B. 1994. What is Rural Tourism?. J. Sustain. Tour. 2(1-2):7-21. https://doi.org/10.1080/09669589409510680

Lee, C.C. and C.P. Chang. 2008. Tourism development and economic growth: A closer look at panels. Tour. Manag.
29(1):180-192. https://doi.org/10.1016/j.tourman.2007.02.013

Lee, Y.G. 2008. Policy network analysis on the processes of making regional innovative clusters - Focus on the Yeongdong grapes cluster-. Master's thesis, University of Seoul, Seoul, Korea.

McCool, S.F., and R.N. Moisey (Eds.). 2001. Tourism, recreation, and sustainability: Linking culture and the environment. Oxon, UK: CABI Publishing.

Pauline, P. 2009. Agritourism in Italy. Melbourne, Australian: International Specialised Skills Institute Inc.

Plummer, R., D. Telfer, and A. Hashimoto. 2006. The rise and fall of the Waterloo-Wellington Ale Trail: A study of collaboration within the tourism industry. Curr. Issues Tour. 9(3):191-205. https://doi.org/10.2167/cit/194.0

Przezborska, L. 2005. Classification of agri-tourism/rural tourism SMEs in Poland (on the example of the Wielkopolska Region) (No. 724-2016-49219). https://doi.org/10.22004 /ag.econ. 24670

Roberts L. and D. Hall. 2001. Rural tourism and recreation: Principles to practice. Oxon, UK: CABI Publishing.

Ruhanen, L. 2013. Local government: facilitator or inhibitor of sustainable tourism development?. J. Sustain. Tour. 21(1):80-98. https://doi.org/10.1080/09669582.2012.680463

Schubert, S.F., J.G. Brida, and W.A. Risso. 2011. The impacts of international tourism demand on economic growth of small economies dependent on tourism. Tour. Manag. 32(2):377-385. https://doi.org/10.1016/j.tourman.2010.0 3.007

Selin, S. 1999. Developing a typology of sustainable tourism partnerships. J. Sustain. Tour. 7(3-4):260-273. https://doi.org/10.1080/09669589908667339

Sharpley, R. 2009. Tourism development and the environment: Beyond sustainability?. London, UK: Earthscan.

Song, M.R. 2013. The possibility of job creation in rural areas and policy tasks. In: Agri-Policy Focus No. 56. Naju, Korea: Korea Rural Economic Institute.

Surabhi, S. 2016. Agritourism as a strategy for the development of rural areas case study of Dungrajya, Southeast Rajasthan, India. J. Med. Dent. Sci. Res. 3(6):35-39

Sznajder, M., L. Przezbórska, and F. Scrimgeour. 2009. Agritourism. Oxon, UK: CABI Publishing.

Timothy, D.J. 1998. Cooperative tourism planning in a developing destination. J. Sustain. Tour. 6(1):52-68. https://doi. 
org/10.1080/09669589808667301

Topçu, E.D. 2007. Agri-tourism as a new element of country planning. Master's thesis, Middle East Technical University, Ankara, Turkey.

Wilson, S., D.R. Fesenmaier, J. Fesenmaier, and J.C. Van Es. 2001. Factors for success in rural tourism development.
J. Travel Res. 40(2):132-138. https://doi.org/10.1177/00 4728750104000203

Yeongdong County. 2011. A case of vitalizing regional economy through the convergence of high added value grapes industry. In: 2011 Vision Leadership Forum. Yeongdong, Korea: Author. 